\title{
Varenicline attenuates cue-induced relapse to alcohol, but not nicotine seeking, while reducing inhibitory response control
}

\author{
Jelte A. Wouda • Danai Riga • Wendy De Vries • Mathijs Stegeman • \\ Yvar van Mourik • Dustin Schetters • Anton N. M. Schoffelmeer • Tommy Pattij • \\ Taco J. De Vries
}

Received: 2 December 2010 /Accepted: 27 January 2011 /Published online: 18 February 2011

(C) The Author(s) 2011. This article is published with open access at Springerlink.com

\begin{abstract}
Rationale Treatment of the most widely abused drugs, nicotine and alcohol, is hampered by high rates of relapse. Varenicline tartrate, an $\alpha 4 \beta 2$ nicotinic receptor partial agonist, is currently prescribed as a smoking cessation aid. However, there is emerging evidence that it may also modulate alcohol seeking and cognitive functioning in rats. Objectives As preclinical data on alcohol taking and relapse are limited, we used a self-administration-reinstatement model to evaluate the effects of varenicline on operant responding for alcohol $(12 \%, v / v)$, intravenous nicotine (40 $\mu \mathrm{g} / \mathrm{kg} / \mathrm{inf}$.), sucrose $(10 \%, w / v)$ and on cue-induced relapse to alcohol and nicotine seeking in rats. At the cognitive level, we assed varenicline's effects on 5-choice serial reaction time task (5-CSRTT) performance with a focus on correct responses (attention) and premature responding (impulsivity), modalities that have previously been associated with addictive behaviour.

Results Varenicline, at doses of 1.5 and $2.5 \mathrm{mg} / \mathrm{kg}$, reduced alcohol and nicotine self-administration and enhanced operant responding for sucrose. At these doses, varenicline reduced cue-induced relapse to alcohol, but not nicotine
\end{abstract}

J. A. Wouda $\cdot$ D. Riga $\cdot$ W. De Vries $\cdot$ M. Stegeman $\cdot$

Y. van Mourik 'D. Schetters · A. N. M. Schoffelmeer • T. Pattij •

T. J. De Vries

Department of Anatomy and Neurosciences, Neuroscience

Campus Amsterdam, VU University Medical Center,

Amsterdam, The Netherlands

J. A. Wouda · T. J. De Vries $(\bowtie)$

Department of Molecular and Cellular Neurobiology,

Center for Neurogenomics and Cognitive Research,

Neuroscience Campus Amsterdam, VU University,

Amsterdam, The Netherlands

e-mail: tj.devries@vumc.nl seeking. In contrast, at $0.5 \mathrm{mg} / \mathrm{kg}$, varenicline facilitated cue-induced nicotine seeking. Similar to nicotine, varenicline increased premature responding at low doses, but had no effect on any of the other behavioural parameters in the 5-CSRTT.

Conclusions Our data indicate that varenicline specifically reduced responding for nicotine and alcohol, but not for natural reinforcers such as sucrose. Interestingly, varenicline strongly attenuated cue-induced relapse to alcohol seeking, but not nicotine seeking. Varenicline may therefore be a promising aid in the treatment of alcohol addiction.

Keywords Varenicline · Self-administration · Relapse · 5-CSRTT $\cdot$ Nicotine $\cdot$ Alcohol

\section{Introduction}

Alcohol and nicotine are the two most widely abused addictive substances. While several pharmacological treatments for alcohol and nicotine dependence are targeted at reducing drug intake, these treatments generally demonstrate limited protection against relapse (Anton et al. 2006; Frishman 2009). In this respect, varenicline, a novel agent currently prescribed to aid smoking cessation, may have a more favourable pharmacological profile than other registered pharmacotherapeuticals, such as bupropion (Gonzales et al. 2006; Jorenby et al. 2006). Varenicline is a partial $\alpha 4 \beta 2$ nicotinic receptor agonist and was developed with the assumption that such agents may possibly diminish the consequences of both nicotine exposure and its absence. Partial $\alpha 4 \beta 2$ nicotinic receptor agonists are postulated to promote smoking cessation by preventing nicotine from binding to the receptor. At the same time, by partial 
activation of $\alpha 4 \beta 2$ nicotinic receptors, such agents would moderately increase mesolimbic dopamine release, which is believed to alleviate craving (Coe et al. 2005; Niaura et al. 2006). Indeed, clinical observations indicate that varenicline is able to (1) reduce withdrawal symptoms and negative affect during abstinence in treatment-seeking smokers, (2) attenuate the subjective rewarding effects of nicotine during a scheduled smoking lapse and (3) increase the number of abstinent days following the smoking lapse in a subgroup of participants (Patterson et al. 2009). Consistent with these clinical findings, preclinical evidence confirms that varenicline effectively reduces nicotine selfadministration in rats (O'Connor et al. 2010; Rollema et al. 2007). Furthermore, in a rat model for relapse, varenicline attenuated nicotine primed relapse to nicotine seeking as well as relapse induced by a combination of a nicotine prime and associated cues. In contrast, varenicline had no effect on cue-induced relapse alone (O'Connor et al. 2010).

Interestingly, recent findings suggest that varenicline may also modulate alcohol seeking and intake in heavy drinking smokers as well as laboratory animals (McKee et al. 2009; Steensland et al. 2007). Consistent with these findings, varenicline was shown to counteract alcohols' enhancing effect on dopamine levels in the nucleus accumbens in rats (Ericson et al. 2009). Lowering dopamine levels in this region has previously been associated with reduced alcohol consumption in rats (Ericson et al. 1998, 2000; Soderpalm et al. 2000). Together, these findings underline the potential of varenicline as a treatment for alcohol use disorders in addition to its efficacy as a smoking cessation aid.

In humans, abstinence and relapse are associated with cognitive deficits (Scheurich 2005). Therefore, cognitive enhancing agents are pursuit as pharmacotherapy targets for addiction (Sofuoglu 2010). In this respect, nicotine receptor (nAChR) agonists are interesting targets, since acute and chronic administration of $\mathrm{nAchR}$ agonists can produce long-lasting cognitive enhancing effects (Buccafusco et al. 2005), such as improvement of working and spatial memory, facilitated associative learning and improved attentional processing (Levin et al. 2006; Rezvani and Levin 2001). For that reason, the putative cognitive enhancing effects of varenicline warrant investigation.

In the current study, we aim to further elucidate the motivational and cognitive effects of varenicline, with a particular focus on the relapse-preventing properties of this compound in an alcohol seeking and taking model. To that end, we tested the effects of varenicline on both selfadministration and relapse to alcohol and nicotine seeking. Moreover, to control for drug specificity, we also evaluated the effects of varenicline on self-administration of the natural reinforcer sucrose. Finally, we employed the 5-choice serial reaction time task (5-CSRTT) to assess possible cognitive enhancing effects of varenicline at the level of visuospatial attention and inhibitory response control (Robbins 2002), the latter being a behavioural trait associated with enhanced motivation to initiate and maintain nicotine selfadministration in rats (Diergaarde et al. 2008).

\section{Methods}

Animals

Male Wistar rats (Harlan CPB, Horst, The Netherlands), weighing 280-320 g upon arrival, were used. They were housed in pairs in a temperature- and humidity-controlled room on a 12-h light/dark cycle (lights on between 7 p.m. and 7 a.m.), with the exception that animals that were implanted with intravenous silicon catheters were individually housed. Catheters were implanted in the right jugular vein under gas anaesthesia (Isoflurane) as described before (De Vries et al. 1999). All training and testing sessions were conducted during the dark phase of the light-dark cycle, at the same time each day. Experimental procedures were approved by the Animal Ethical Committee of the VU University, Amsterdam, The Netherlands.

Apparatus and behavioural procedure

\section{Self-administration}

Self-administration training and testing was conducted in 32 identical operant chambers enclosed in soundattenuating ventilated cubicles (Med Associates Inc., St. Albans, VT, USA). The operant chambers were equipped with a grid floor, two nose poke holes and a central reinforcer receptacle; a dim red house light and a tone module (ENV-223AM Med Associates Inc.) were fitted on the opposite wall. During self-administration, reinforcers were delivered by an infusion pump (PHM-100, Med Associates Inc.).

Animals were placed in the operant chamber, and after $30 \mathrm{~s}$, the house light was switched on and trials started. Each trial was signalled by illumination of a red stimulus light located above the active hole, which was extinguished when a nose poke was made into this hole. An active nose poke resulted either in an intravenous (i.v.) infusion of nicotine $(40 \mu \mathrm{g} / \mathrm{kg})$, the delivery of $0.2 \mathrm{ml}$ alcohol $(12 \%$, $v / v$ ) or $0.2 \mathrm{ml} 10 \%$ sucrose in the receptacle, and a yellow stimulus light in the nose poke hole was illuminated for $5 \mathrm{~s}$ combined with a 2-s tone signal $( \pm 68 \mathrm{~dB}, 2,900 \mathrm{~Hz})$. After delivery, a time-out period of $15 \mathrm{~s}$ commenced, during which, all stimulus lights were switched off until the next trial started. Responding during time-out was monitored, but had no programmed consequences. 


\section{Two-bottle procedure}

To facilitate acquisition of operant alcohol self-administration, rats were first trained to consume alcohol in a two-bottle freeaccess paradigm. In this paradigm, upon arrival, rats were habituated to two water bottles on their home cages. Every other day, one of the bottles was replaced by a bottle containing a gradually increasing alcohol solution (from $2 \%$ to $12 \%, v / v$ ). In three weeks, the animals reached $12 \%, v / v$ alcohol, and training proceeded to a two-bottle limited-access paradigm, i. e. animals were given access to the $12 \%$ solution for $1 \mathrm{~h}$ daily. After 10 days of limited access, animals that consumed over $0.35 \mathrm{~g} / \mathrm{kg}$ alcohol were selected to enter the operant selfadministration phase.

\section{5-Choice serial reaction time task}

Experiments were conducted in rat operant chambers with stainless steel grid floors (MED-NPW-5L; Med Associates Inc.). On-line control of all operant chambers and data collection were performed using MED-PC version IV (Med Associates Inc.). Five sessions were scheduled per week from Monday until Friday, one session per day.

A more detailed description of training in the 5-CSRTT has been reported previously (van Gaalen et al. 2006). In short, rats were trained to detect and respond to a 1-s visual stimulus in either one of five apertures, during presentation of the stimulus or during the 2-s limited hold period, to obtain a food pellet (45 mg, Formula P; Research Diets Inc., New Brunswick, NJ, USA). Each session terminated after 100 trials or $30 \mathrm{~min}$, whichever occurred first. Initially, the duration of this stimulus was $32 \mathrm{~s}$ and was gradually decreased to $1 \mathrm{~s}$ over sessions until animals reached stable baseline performance (accuracy $>80 \%$ correct choice and $<20 \%$ errors of omission). Incorrect, premature responses (responses during the 5-s inter-trial interval (ITI)) and errors of omission did not lead to the delivery of a food pellet and resulted in a 5-s time-out period, during which, the house light was extinguished. Responses during the time-out period resulted in a new time-out period. Perseverative responses, i.e. repeated responding into an aperture following correct choice and before pellet collection, were measured but did not have any programmed consequences. The following behavioural measures were recorded: (1) accuracy ((number correct trials/(correct + incorrect trials)) 100); (2) latency of correct responses, i.e. the mean time between stimulus onset and nose poke in the illuminated unit; (3) premature responses, i.e. the number of premature responses before the onset of the visual stimulus, reflecting aspects of loss of inhibitory control (impulsivity) and (4) perseverative responses after correct choice, a measure of compulsive behaviour; (5) omission errors, i.e. the total number of omitted trials during a session.
Experimental design

\section{Self-administration}

In three separate experiments, we tested the effects of varenicline on either nicotine $(\exp 1)$, alcohol $(\exp 2)$ or sucrose (exp 3) self- administration. Behavioural training started 1 week after surgery (nicotine), two-bottle procedure (alcohol) or arrival (sucrose). Initially, all animals were trained daily in 1-h sessions on a continuous reinforcement schedule. The fixed ratio was increased during training, up to FR3 for the nicotine groups and FR4 for alcohol and sucrose groups. When the levels of responding met predefined selection criteria, the effect of a graded dose of varenicline on self-administration was tested. Criterion performance was defined as follows. For the nicotine group, animals that received five or more reinforcers, distributed over the session during the last three sessions on a FR3 schedule, were selected for testing. In the alcohol group, animals that self-administered over $0.35 \mathrm{~g} / \mathrm{kg}$ alcohol for three consecutive days on a FR4 schedule of reinforcement were selected for testing. In the sucrose group, all animals received five or more reinforcers, distributed over the session during the last three sessions on a FR4 schedule and were selected for testing.

Varenicline tests were conducted twice a week, on Tuesdays and Fridays. On intermediate days, rats were trained to self-administer nicotine, alcohol or sucrose without being treated with varenicline. To explore the effects of varenicline on self-administration, a withinsubject design was used, and treatment was randomized over the subjects using a Latin square design.

To facilitate acquisition, the alcohol group (exp 2) was given a single 20-min habituation session on the first training day, during which, only the house light was illuminated. Nose poking during this session was without any behavioural consequences. Furthermore, these animals received one free sample of alcohol in the central receptacle upon the start of the habituation session and the first five training sessions.

\section{Cue-induced relapse}

To asses the effects of varenicline on cue-induced relapse to nicotine or alcohol seeking, two separate groups of animals were trained to criterion performance and subsequently underwent extinction training. Thus, animals were placed in the training context for 15 daily sessions of $1 \mathrm{~h}$, without audiovisual cue-exposure or reinforcer delivery.

Relapse Rats were divided into four experimental groups that received either vehicle, $0.5,1.5$ or $2.5 \mathrm{mg} / \mathrm{kg}$ varenicline. On the test day, all animals were injected with 
vehicle or one of three doses $30 \mathrm{~min}$ before they were placed in the training context for a 30-min relapse test. During the relapse test, the house light and red cue light were turned on, and nose poking resulted in the presentation of the discrete compound audiovisual cues (but no reinforcer delivery) on the FR schedule used during training. In the alcohol group, $0.20 \mathrm{ml}$ alcohol $(12 \%, v / v)$ was delivered in the receptacle before the session started. We conducted a series of pilot studies investigating cueinduced alcohol seeking under several conditions. Data from these studies and work by others indicate that adding a single drop of alcohol, that induces the gustatory, but not the pharmacological effects of alcohol, results in optimal relapse (Le and Shaham 2002).

\section{5-Choice serial reaction time task}

To assess putative cognitive enhancing effects of varenicline, rats were trained in the 5-CSRTT until they reached stable baseline performance on stimulus duration $1 \mathrm{~s} \mathrm{(accu-}$ racy $>80 \%$ correct choice and $<20 \%$ errors of omission during the last five sessions). Subsequently, the effects of varenicline were assessed using a Latin square design, and tests were conducted twice a week, on Tuesdays and Fridays. On intermediate days, rats were trained normally without being treated with varenicline. Following the tests with varenicline, animals were trained for an additional week and tested under increased attentional demand by reducing the stimulus duration to $0.5 \mathrm{~s}$. Subsequently, under these conditions, the effect of $1.5 \mathrm{mg} / \mathrm{kg}$ varenicline was tested.

\section{Drugs}

Nicotine hydrogen tartrate salt (Sigma, St Louis, MO, USA) was dissolved in sterile saline, and the $\mathrm{pH}$ of the solution was adjusted to \pm 7.4 with diluted $\mathrm{NaOH}$. The nicotine dose is expressed as free base weight. For all alcohol solutions used, 96\% laboratory alcohol (Interchema, Oosterzee, the Netherlands) was diluted with water to reach the appropriate concentrations. Varenicline (kindly provided by Solvay Pharmaceuticals, Weesp, the Netherlands) was suspended in a $1 \%$ methylcellulose- $5 \%$ mannitol solution, and the $\mathrm{pH}$ was adjusted to 7.9. In all studies, varenicline was administered intraperitoneally with an injection volume of $2 \mathrm{ml} / \mathrm{kg}, 30 \mathrm{~min}$ before testing, and doses were $0.5,1.5$ and $2.5 \mathrm{mg} / \mathrm{kg}$ based on previous studies (Rollema et al. 2007; Steensland et al. 2007).

\section{Statistical analyses}

All statistical analyses were performed using the Statistical Package for the Social Sciences version 15.0 (SPSS Inc.,
Chicago, IL, USA), and all data are displayed as mean \pm SEM. The homogeneity of variance across groups was determined using Mauchly's tests for equal variances and in case of violation of homogeneity, corrected Huynh-Feldt degrees of freedom and resulting more conservative probability values were used for subsequent analyses. In case of statistically significant main effects, further post hoc comparisons were conducted using Student-NewmanKeuls tests. The level of probability for statistically significant effects was set at 0.05 .

For the self-administration data, the dependent variables (i.e. total number of nose poke responses in the active and inactive hole and number of reinforcers) were analyzed using a repeated measures analysis of variance (ANOVA) with varenicline doses as within-subject factor. For the relapse experiments, a between-subject design was employed; thus, the different doses of varenicline served as between-subject factors. Data obtained in the 5-CSRTT were subjected to repeated measures ANOVA with varenicline treatment as a within-subject factor.

\section{Results}

Experiment 1: nicotine self-administration

To investigate the effects of varenicline on nicotine selfadministration, 16 rats were trained to nose-poke for intravenous nicotine infusions in the presence of audiovisual cues. Six animals were excluded because they did not meet the selection criteria or had clogged catheters. Varenicline treatment had an overall main effect on the total number of active nose pokes $(F(3,27)=36.04, p<$ 0.001 ), and further post hoc analyses revealed that 1.5 and $2.5 \mathrm{mg} / \mathrm{kg}$ varenicline significantly reduced nicotine selfadministration compared to vehicle (Fig. 1a). Varenicline treatment also affected the total number of inactive responses $(F(3,27)=2.98, p<0.05)$. Post hoc analyses revealed that inactive responding did not differ from vehicle treatment for any of the varenicline doses; however, the $2.5-\mathrm{mg} / \mathrm{kg}$ dose significantly reduced the number of inactive responses compared to $0.5 \mathrm{mg} / \mathrm{kg}$ varenicline.

Experiment 2: alcohol self-administration

In experiment 1 , varenicline was able to dose-dependently reduce nicotine self-administration. To investigate its effects on alcohol self-administration, a separate group of 16 animals was trained. Twelve animals met our selection criteria. Varenicline treatment had an overall main effect on operant self-administration of alcohol $(F(3,33)=7.65, p<$ 0.001 ), and post hoc analyses revealed that 1.5 and $2.5 \mathrm{mg} / \mathrm{kg}$ varenicline significantly reduced alcohol self-administration 


\section{a Nicotine Self-administration}
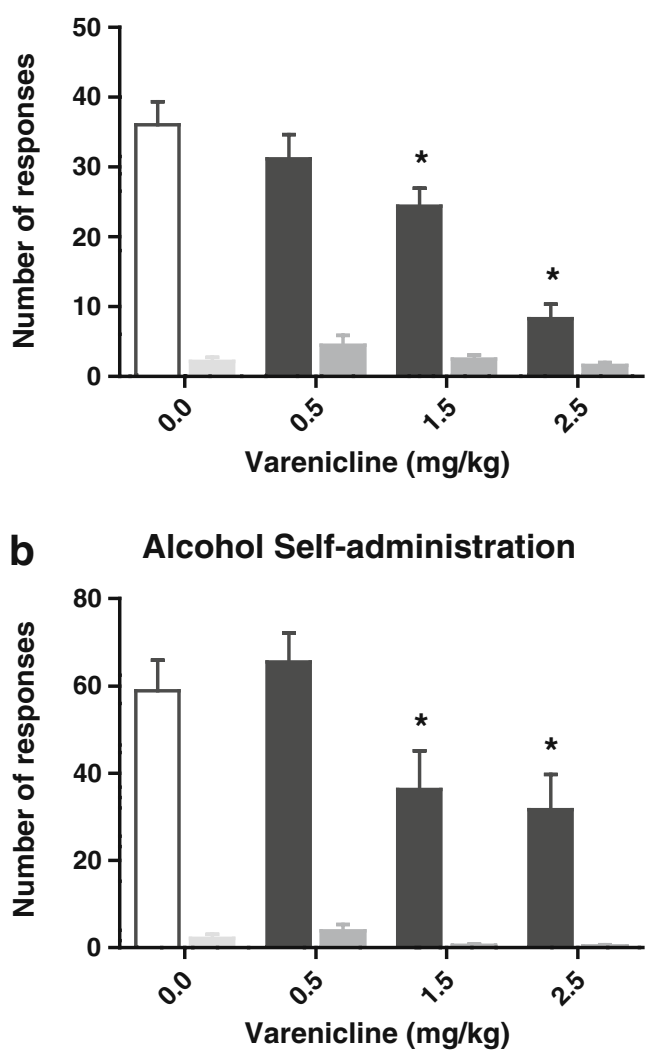

C Sucrose Self-administration

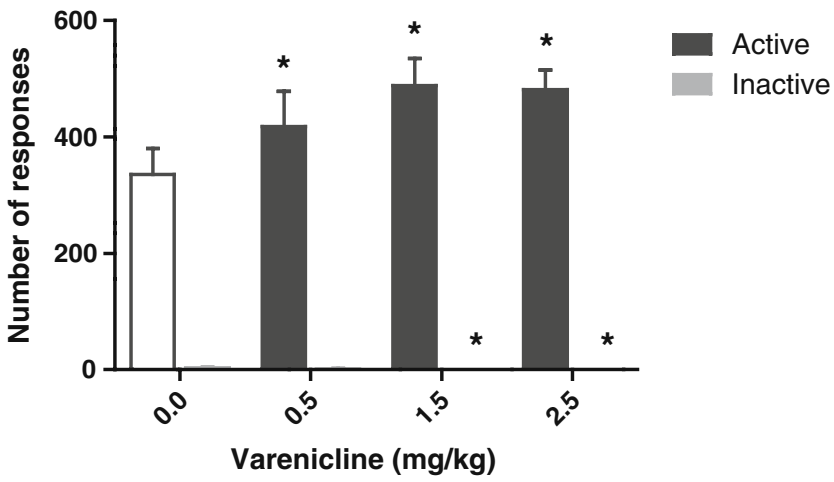

Fig. 1 Effects of varenicline on self-administration of a nicotine, $\mathbf{b}$ alcohol and $\mathbf{c}$ sucrose (inactive responses sucrose self-administration (mean \pm SEM): $0.0 \mathrm{~g} / \mathrm{kg}, 3 \pm 1.6 ; 0.5 \mathrm{~g} / \mathrm{kg}, 1.7 \pm 0.5 ; 1.5 \mathrm{~g} / \mathrm{kg}, 0.1 \pm 0.1$; $2.5 \mathrm{~g} / \mathrm{kg}, 0.1 \pm 0.1) .{ }^{*} p<0.05$ significant difference with respect to $0.0 \mathrm{~g} / \mathrm{kg}$ group

compared to vehicle (Fig. 1b). In addition, a main effect of varenicline treatment was also found on the total number of inactive responses $(F(3,33)=3.96, p<0.05)$. Post hoc analyses revealed that inactive responding did not differ from saline treatment for any of the varenicline doses; however, both treatment with 1.5 and $2.5 \mathrm{mg} / \mathrm{kg}$ varenicline significantly reduced the number of inactive responses compared to treatment with $0.5 \mathrm{mg} / \mathrm{kg}$ varenicline.
Experiment 3: sucrose self-administration

To assess whether varenicline treatment selectively affects nicotine and alcohol self-administration over responding for natural reinforcers, eight rats were trained to nose-poke for $10 \%$ sucrose reinforcers in the presence of audiovisual cues. All animals acquired stable self-administration of sucrose. Varenicline had an overall main effect on operant self-administration of sucrose $(F(3,21)=6.61, p<0.01)$, and post hoc analyses revealed that all varenicline doses significantly increased sucrose self-administration compared to vehicle (Fig. 1c). In addition, a main effect of varenicline treatment was also found for the total number of inactive responses $(F(3,21)=3.49, p<0.05)$. Post hoc analyses revealed that only treatment with $2.5 \mathrm{mg} / \mathrm{kg}$ varenicline significantly reduced the number of inactive responses compared to vehicle treatment.

Experiment 4: nicotine relapse

To assess whether varenicline would be protective against relapse to nicotine seeking, we investigated its effects on cue-induced relapse after extinction. Fifty-four animals met the selection criteria and were divided into four groups (vehicle $(n=18), 0.5 \mathrm{mg} / \mathrm{kg}(n=12), 1.5 \mathrm{mg} / \mathrm{kg}(n=12)$ or $2.5 \mathrm{mg} / \mathrm{kg}(n=12)$ varenicline). The different experimental groups displayed equivalent levels of active responding during the last 2 days of training and extinction (data not shown). Varenicline had an overall main effect on cueinduced relapse to nicotine self-administration $(F(3,50)=$ $4.28, p<0.01$; Fig. 2a). Further comparisons revealed that the $0.5-\mathrm{mg} / \mathrm{kg}$ dose increased responding for nicotine cues compared to vehicle and $2.5 \mathrm{mg} / \mathrm{kg}(p<0.05)$. Treatment with $2.5 \mathrm{mg} / \mathrm{kg}$ varenicline significantly reduced the number of active responses compared to treatment with $0.5 \mathrm{mg} / \mathrm{kg}$ varenicline. A treatment effect was also found for inactive responses $(F(3,50)=2.98, p<0.05)$. Post hoc analyses revealed an increase in inactive responding in the $0.5-\mathrm{mg} / \mathrm{kg}$ varenicline group compared to all other groups.

Experiment 5: alcohol relapse

Before the cue-induced relapse test was conducted, the different experimental groups (vehicle $(n=10), 0.5 \mathrm{mg} /$ $\mathrm{kg}(n=10), 1.5 \mathrm{mg} / \mathrm{kg}(n=10)$ or $2.5 \mathrm{mg} / \mathrm{kg} \quad(n=10)$ varenicline) displayed equivalent levels of active responding during the last 2 days of training and extinction (data not shown). Varenicline had an overall main effect on relapse to alcohol seeking $(F(3,36)=13.63, p<0.001)$, and post hoc analyses revealed that 1.5 and $2.5 \mathrm{mg} / \mathrm{kg}$ varenicline significantly reduced relapse to alcohol seeking compared to vehicle, whereas the $0.5 \mathrm{mg} / \mathrm{kg}$ dose seemed to induce a slight, but non-significant increase in 
Fig. 2 Effects of varenicline on cue-induced reinstatement of $\mathbf{a}$ nicotine and $\mathbf{b}$ alcohol seeking. ${ }^{*} p<0.05$ significant difference with respect to $0.0 \mathrm{~g} / \mathrm{kg}$ group
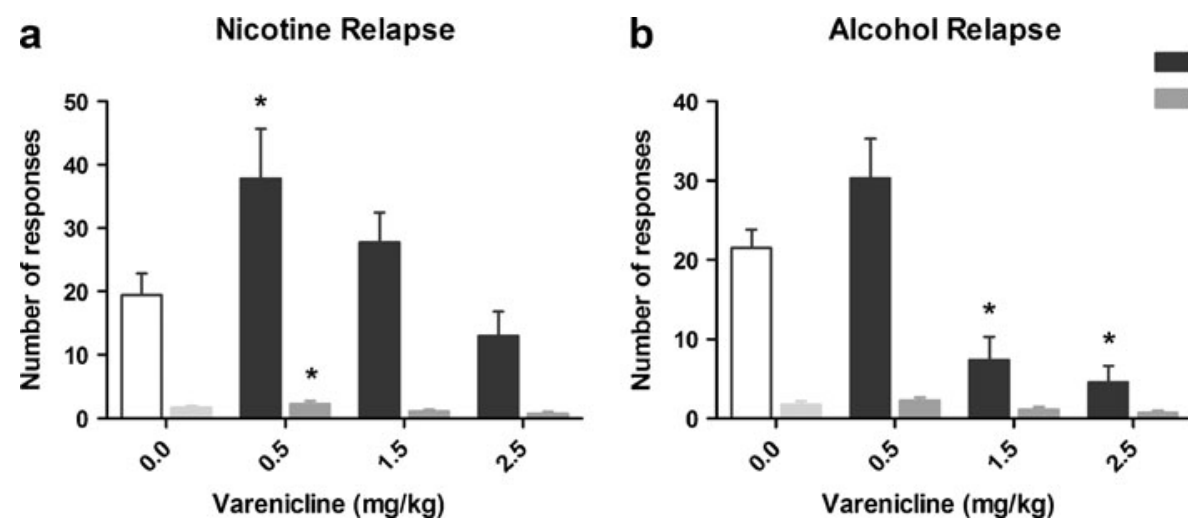

alcohol seeking ( $p=0.07$; Fig. $2 \mathrm{~b})$. Varenicline treatment did not affect inactive responding $(F(3,36)=0.60, p=0.618)$.

\section{Experiment 6: 5-CSRTT}

To assess putative cognitive-enhancing effects of varenicline, 16 rats were trained in the 5-CSRTT. Varenicline treatment had a main effect on attention $(F(3,45)=3.92, p<$ $0.05)$, premature responding $(F(3,45)=3.15, p<0.05)$ and correct response latency $(F(3,45)=2.28, p<0.05)$, but not on the number of omissions $(F(3,45)=2.28, p=0.1$; Fig. 3$)$. Post hoc analyses showed that the number of premature responses was increased by the $0.5-$ and $1.5-\mathrm{mg} / \mathrm{kg}$ dose of varenicline $(p<0.05)$, whereas the $2.5-\mathrm{mg} / \mathrm{kg}$ dose tended to increase the number of premature responses $(p=0.06)$. With regard to the effects on attention and correct response latencies, post hoc analyses revealed no significant effects of any dose compared to vehicle. However, $2.5 \mathrm{mg} / \mathrm{kg}$ varenicline did increase correct response latency compared to the $0.5-$ and $1.5-\mathrm{mg} / \mathrm{kg}$ dose.

To investigate whether varenicline would enhance performance under conditions of increased attentional load, the effect of $1.5 \mathrm{mg} / \mathrm{kg}$ varenicline was tested in combination with a reduced stimulus duration of $0.5 \mathrm{~s}$. Increasing the attentional load by reducing the stimulus duration from 1 to $0.5 \mathrm{~s}$ reduced accuracy $(F(1,15)=36.94, p<0.001)$, shortened response latencies $(F(1,15)=13.62, p<0.01)$ and increased omission rate $(F(1,15)=69.40, p<0.001)$, whereas premature responding remained unaffected $(F(1,15)=$ $2.3, p=0.15$; Fig. 4). In accordance with the aforementioned results, $1.5 \mathrm{mg} / \mathrm{kg}$ varenicline increased the number of premature responses $(F(1,15)=27.45, p<0.001)$, but did not alter accuracy $(F(1,15)=1.42, p=0.25)$ or correct response latencies $(F(1,15)=1.65, p=0.20)$. A reduction of omissions was seen after varenicline treatment $(F(1,15)=15.11, p<$ $0.001)$. Furthermore, a treatment $\times$ stimulus duration interaction effect for correct response latency was found $(F(1,15)=6.00, p<0.05)$. Post hoc analyses indicated that the reduction of correct response latencies induced by increased attentional load was less pronounced following varenicline treatment. None of the other parameters showed a treatment $\times$ stimulus duration interaction (accuracy, $F$ $(1,15)<1, p=0.85$; omissions, $F(1,15)=1.83, p=0.20)$; premature responding, $F(1,15)=1.89, p=0.15)$.

\section{Discussion}

In the present study, we evaluated the effects of varenicline on both motivational processes (nicotine, alcohol and sucrose seeking) and cognitive functions (visuospatial attention and inhibitory response control) in rats. We confirm earlier observations demonstrating that varenicline attenuates nicotine and alcohol self-administration (O'Connor et al. 2010; Rollema et al. 2007; Steensland et al. 2007). In contrast, selfadministration of the natural reinforcer sucrose was increased by varenicline. Importantly, we demonstrate for the first time that varenicline dose-dependently reduces cueinduced relapse to alcohol seeking. Interestingly, cueinduced relapse to nicotine seeking was not affected by the higher doses, and the lowest dose of varenicline $(0.5 \mathrm{mg} / \mathrm{kg})$ increased responding for nicotine-associated cues. At the cognitive level, we show that varenicline reduces inhibitory response control without affecting measures of visuospatial attention in a 5-choice serial reaction time task (5-CSRTT).

In the treatment of drug addiction, relapse after abstinence represents a major problem. Ideally, pharmacotherapies for drug addiction would aid the cessation of drug intake and prevent relapse. As both preclinical and clinical data indicate that varenicline may potentially posses both characteristics (Gonzales et al. 2006; Jorenby et al. 2006; O'Connor et al. 2010; Patterson et al. 2009; Rollema et al. 2007, 2009; Steensland et al. 2007; Tonstad et al. 2006; Tonstad 2006), we determined the anti-relapse properties of varenicline in a so-called self-administration-reinstatement model (Shaham et al. 2003). Remarkably, we found that varenicline strongly attenuated cue-induced alcohol seeking at the same doses that reduced alcohol self-administration. This finding suggests that varenicline has putative protec- 
Fig. 3 Effects of varenicline on 5-choice serial reaction time performance. The following behavioural measures are presented: a percentage correct responses (attention), b number of premature responses (impulsivity), c number of omissions and $\mathbf{d}$ latency of correct responses. ${ }^{*} p<0.05$ significant difference with respect to $0.0 \mathrm{~g} / \mathrm{kg}$ group

\section{a}

Attention
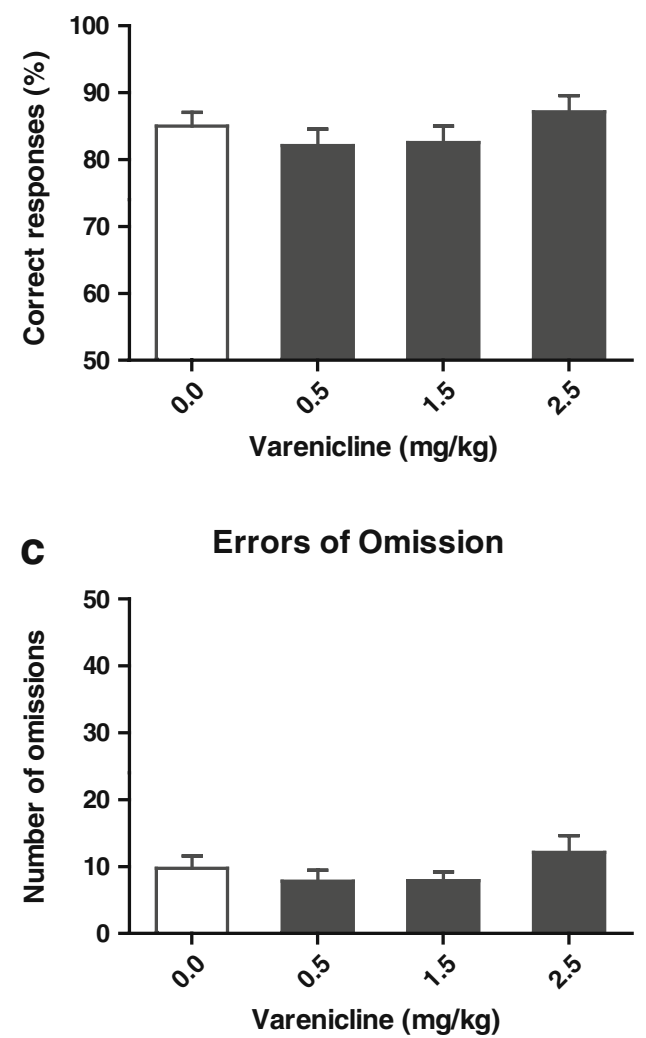

b Impulsivity

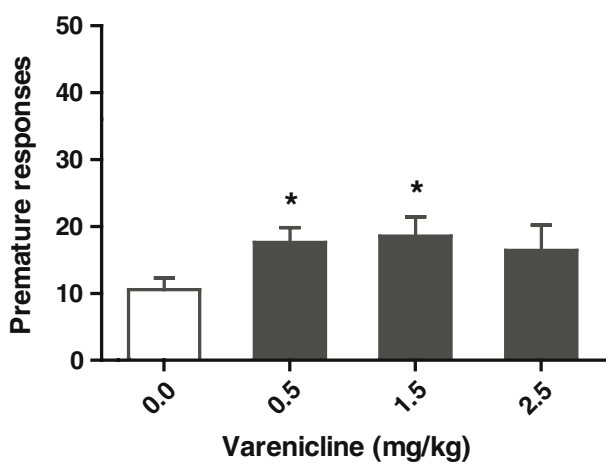

d Correct response latency

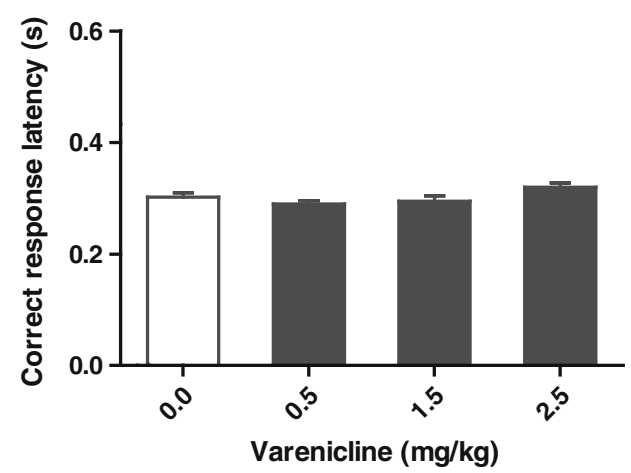

tive effects against relapse to alcohol use, an important addition to the growing body of evidence that underlines the potential of varenicline as a treatment for alcohol use disorders.

How varenicline modulates the neurobiological mechanisms that mediate cue-induced relapse to alcohol seeking remains to be unravelled. Pharmacological studies have identified several neurotransmitter systems that appear to be involved in alcohol relapse, including the glutamate, opioid, serotonin and dopamine system. In particular, activation of the mesolimbic dopamine system and alterations in excitatory amino acid neurotransmission may underlie relapse to alcohol seeking (Le and Shaham 2002). Since varenicline was reported to affect dopamine release in the nucleus accumbens (Coe et al. 2005; Ericson et al. 2009; Rollema et al. 2007), it may alter relapse to alcohol seeking by modulating dopaminergic neurotransmission in the mesolimbic pathway.

In a separate experiment, we assessed the effects of varenicline on cue-induced relapse to nicotine seeking. Remarkably, we found that varenicline, at doses that diminished relapse to alcohol seeking, did not reduce cueinduced relapse to nicotine seeking. These results are consistent with recent findings of O'Connor et al. (2010). Furthermore, we found enhanced cue-induced relapse at a dose of $0.5 \mathrm{mg} / \mathrm{kg}$. Interestingly, a similar but nonsignificant $(p=0.07)$ effect was seen on alcohol seeking.
Thus, it seems that varenicline affects cue-induced relapse in a bimodal fashion. A possible explanation may be that the anti-relapse effect is mediated by receptors other than the $\alpha 4 \beta 2$ nACh subtype that are activated at higher doses, while at low doses, varenicline induces a priming effect via $\alpha 4 \beta 2$ nACh receptors. Indeed, varenicline was shown to be a (partial) agonist for other $\mathrm{nACh}$ receptor subtypes, such as $\alpha 7$ and at higher doses $\alpha 3 \beta 4, \alpha 3 \beta 2$ and $\alpha 6$ receptors, albeit with much lower affinity (Coe et al. 2005; Mihalak et al. 2006). Hence, varenicline may activate additional nAch receptor subtypes at 1.5 and $2.5 \mathrm{mg} / \mathrm{kg}$ (Rollema et al. 2009).

Regarding varenicline's effects on self-administration, our findings confirm that varenicline dose-dependently attenuates nicotine self-administration. Substantial evidence indicates that varenicline may affect nicotine selfadministration by reducing nicotine-induced mesolimbic dopamine release (Coe et al. 2005; Rollema et al. 2007). In agreement with results from Steensland et al. (2007), our data suggest that varenicline has a comparable effect on alcohol self-administration. Similarly, co-administration of varenicline and alcohol counteracted each other's respective enhancing effect on dopamine levels in the nucleus accumbens (Ericson et al. 2009). Nonetheless, it remains to be determined whether varenicline's attenuating effect on alcohol and nicotine self-administration is mediated by the same molecular mechanisms. As mentioned before, vareni- 
Fig. 4 Effects of varenicline $(1.5 \mathrm{mg} / \mathrm{kg})$ on 5 -choice serial reaction time performance under increased attentional load by reduced stimulus duration. The following behavioural measures are presented: a percentage correct responses (attention), b number of premature responses (impulsivity), $\mathbf{c}$ number of omissions and d latency of correct responses. ${ }^{*} p<0.05$ significant difference with respect to $0.0 \mathrm{~g} / \mathrm{kg}$ group. $\# p<0.05$ significant difference with respect to stimulus duration $1.0 \mathrm{~s}$
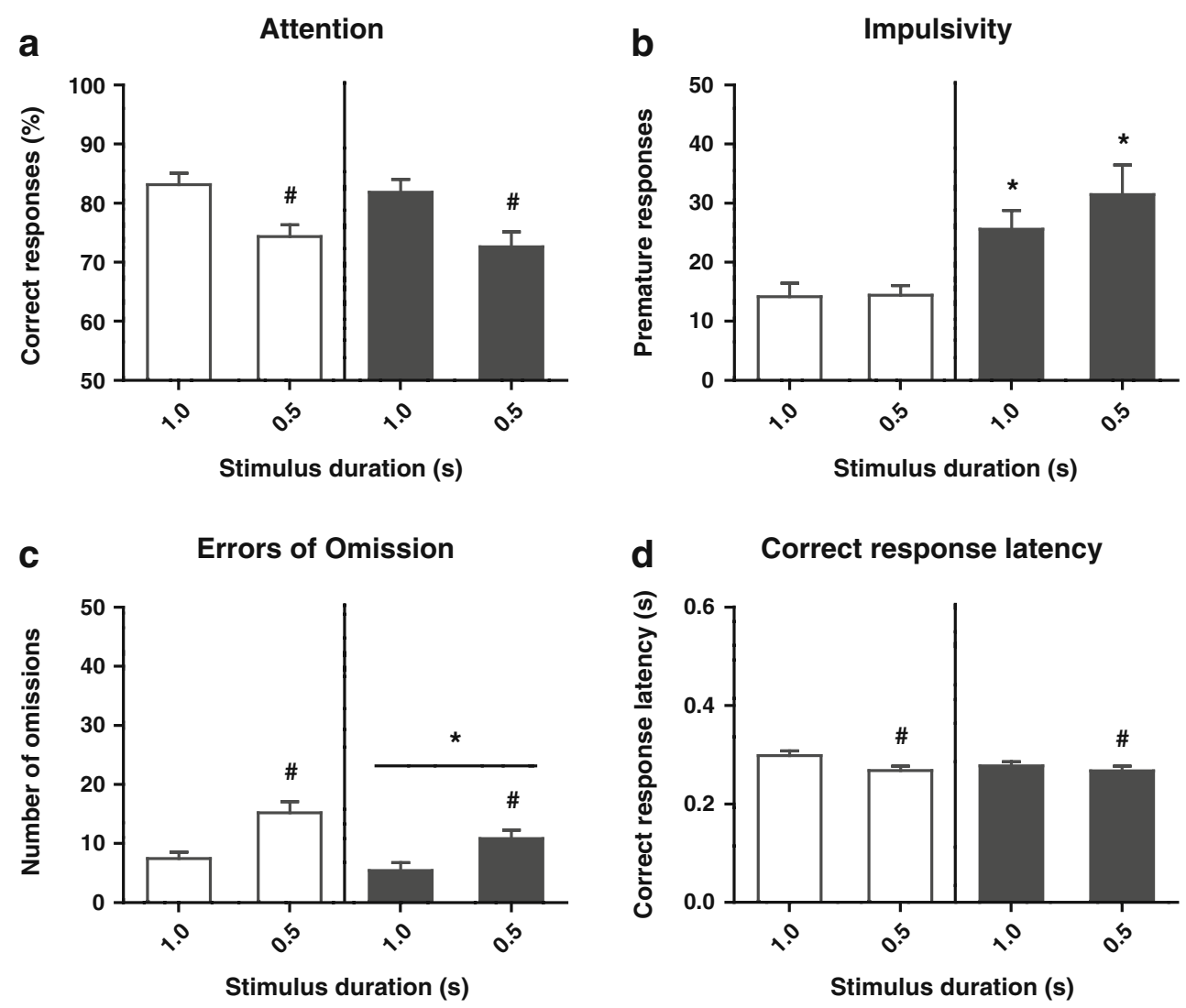

Varenicline $1.5 \mathrm{mg} / \mathrm{kg}$ cline is known to have limited selectivity for different nACh receptor subtypes (Coe et al. 2005; Mihalak et al. 2006). Some of these receptor subtypes are implicated in the reinforcing effects of alcohol (Chastain 2006; Davis and de Fiebre 2006; Ericson et al. 2009; Jerlhag et al. 2006; Larsson et al. 2004; Lof et al. 2007). Particularly, the $\alpha 3 \beta 4$ nAch receptor seems a likely candidate for the modulation of alcohol intake (Chatterjee et al. 2010). Therefore, we cannot exclude the notion that varenicline differentially mediates its effects on nicotine and alcohol selfadministration via receptors other than the $\alpha 4 \beta 2 \mathrm{nACh}$ receptor.

To determine whether the attenuating effects of varenicline were selective for alcohol and nicotine and/or due to a reduced ability to make an operant response, we assed its effects on operant responding for the natural reinforcer sucrose. Interestingly, sucrose self-administration was augmented by varenicline at doses that significantly reduced nicotine and alcohol self-administration. Previous studies investigating intake of natural reinforcers have not reported such effects (O'Connor et al. 2010; Steensland et al. 2007). Varenicline was however reported to increase responding for food delivery in rats trained on a variable interval reinforcement schedule (Rollema et al. 2007). A role for $\mathrm{nACh}$ receptors in sucrose seeking, however, is not supported by previous data, i.e. nACh receptor agonists and antagonists have not been reported to attenuate sucrose intake (Ford et al. 2009; Hendrickson et al. 2009; Nadal et al. 1998; Neugebauer et al. 2006; Steensland et al. 2007).

Collectively, these findings imply the following. First, that varenicline selectively attenuates self-administration of alcohol and nicotine, an effect that does not generalize to self-administration of food or sucrose. In fact, our findings suggest that varenicline affects operant responding for natural reinforcers and addictive substances, i.e. nicotine and alcohol, in opposite directions. Second, as varenicline treatment did not impair sucrose self-administration, varenicline's effects on consumption of addictive substances are most probably due to changes in the motivational domain, rather than impaired abilities to perform an operant response.

In humans, varenicline was shown to enhance cognitive functioning during abstinence of smoking/drinking. Although the effects were small, varenicline improved sustained attention (as measured by the Penn Continuous Performance Task) and working memory (as measured by the letter N-back task; Patterson et al. 2009). Furthermore, recent rodent studies show that varenicline may ameliorate alcoholinduced cognitive deficits in acquisition of contextual and cued associative learning in mice (Gulick and Gould 2008) 
and improve attentional performance in a sustained attention task with distractor stimuli in rats (Rollema et al. 2009). We used the 5-choice serial reaction time task (5-CSRTT) to further explore the effects of varenicline on cognition. Previous research from our and other laboratories revealed that nicotine positively affects cognitive function as measured in the 5-CSRTT by (1) enhancing sustained attention under certain conditions, (2) decreasing response latency and (3) reducing the number of omissions. On the other hand, nicotine deteriorates inhibitory control in this task as measured by an increase in premature responding (Blondel et al. 2000; Day et al. 2007; Mirza and Stolerman 1998; van Gaalen et al. 2006). In the current study, we found no evidence for cognitive-enhancing effects of varenicline. However, varenicline increased premature responding, albeit to a lesser extent than nicotine (Blondel et al. 2000; Mirza and Stolerman 1998; van Gaalen et al. 2006). This effect may result from enhanced dopaminergic neurotransmission in the mesolimbic pathway induced by $\mathrm{nACh}$ receptor activation in the nucleus accumbens or ventral tegmental area (Di Chiara and Imperato 1988; Marshall et al. 1997; Nisell et al. 1994; Wonnacott 1997), that in turn has been demonstrated to modulate premature responding in the 5-CSRTT (Cole and Robbins 1987; Pattij et al. 2007). It should be noted here that detrimental effects of varenicline on inhibitory response control may be unfavourable during treatment in humans, as previous research from our laboratory has associated poor inhibitory response control with an enhanced motivation to initiate and maintain nicotine self-administration in rats (Diergaarde et al. 2008). Likewise, in line with these preclinical findings, diminished inhibitory control has been demonstrated to predict unsuccessful smoking cessation in abstinent smokers (KrishnanSarin et al. 2007). Interestingly, recent findings from our laboratory suggest that under comparable conditions, no such association exists between inhibitory response control and alcohol self-administration in rats (Diergaarde, unpublished). The strong relationship between impulsivity and nicotine, but not alcohol seeking, together with the observation that varenicline diminishes inhibitory control may partly explain the differential effects of this compound on relapse to alcohol and nicotine seeking.

We also tested varenicline in combination with a reduced stimulus duration $(0.5 \mathrm{~s}$ instead of $1 \mathrm{~s})$ to assess its effects on performance under increased attentional load. Compared to saline treatment, varenicline was unable to improve attentional performance under these challenging conditions. This seems to contradict previous data demonstrating that varenicline significantly improved the capacity to attenuate impaired performance under challenging distractor conditions in a sustained attention task (Rollema et al. 2009). Specific differences between the 5-CSRTT and the sustained attention task may explain this discrepancy. In particular, in the sustained attention task, an auditory stimulus was used to reduce the discriminability of a visual cue, whereas in the 5-CSRTT, the signal duration of a visual cue was reduced. It is possible that varenicline reduces the impact of a distractor on signal detection, but does not improve sustained attention. Taken together, varenicline's effects on cognitive functions as measured in the 5-CSRTT seem limited and less pronounced than the effects of nicotine, consistent with its lower efficacy at the $\mathrm{nACh}$ receptor.

In summary, this is the first report to demonstrate that, in rats, varenicline attenuates cue-induced alcohol seeking. Furthermore, at lower doses, varenicline may facilitate nicotine seeking. As was previously shown, varenicline may selectively reduce voluntary nicotine and alcohol intake. Moreover, varenicline has limited effects on cognitive functioning as measured by the 5-CSRTT, although varenicline may somewhat reduce inhibitory response control. Such a behavioural pharmacological profile emphasizes varenicline's potential as a pharmacotherapeutical agent in the treatment of alcohol dependence.

Acknowledgements Our research was supported by a ZONMW Topgrant 912-06-148.

Disclosure All authors declare that, except for income received from primary employer, no financial support or compensation has been received from any individual or corporate entity over the past 3 years for research or professional service, and there are no personal financial holdings that could be perceived as constituting a potential conflict of interest.

Open Access This article is distributed under the terms of the Creative Commons Attribution Noncommercial License which permits any noncommercial use, distribution, and reproduction in any medium, provided the original author(s) and source are credited.

\section{References}

Anton RF, O'Malley SS, Ciraulo DA, Cisler RA, Couper D, Donovan DM, Gastfriend DR, Hosking JD, Johnson BA, LoCastro JS, Longabaugh R, Mason BJ, Mattson ME, Miller WR, Pettinati HM, Randall CL, Swift R, Weiss RD, Williams LD, Zweben A (2006) Combined pharmacotherapies and behavioral interventions for alcohol dependence: the COMBINE study: a randomized controlled trial. JAMA 295:2003-2017

Blondel A, Sanger DJ, Moser PC (2000) Characterisation of the effects of nicotine in the five-choice serial reaction time task in rats: antagonist studies. Psychopharmacol Berl 149:293-305

Buccafusco JJ, Letchworth SR, Bencherif M, Lippiello PM (2005) Long-lasting cognitive improvement with nicotinic receptor agonists: mechanisms of pharmacokinetic-pharmacodynamic discordance. Trends Pharmacol Sci 26:352-360

Chastain (2006) Alcohol, neursotransmitter systems and behavior. J Gen Psychol 133:329-335

Chatterjee S, Steensland P, Simms JA, Holgate J, Coe JW, Hurst RS, Shaffer CL, Lowe J, Rollema H, Bartlett SE (2011) Partial 
agonists of the $\alpha 3 \beta 4^{*}$ neuronal nicotinic acetylcholine receptor reduce ethanol consumption and seeking in rats. Neuropsychopharmacology 36:603-615

Coe JW, Brooks PR, Vetelino MG, Wirtz MC, Arnold EP, Huang J, Sands SB, Davis TI, Lebel LA, Fox CB, Shrikhande A, Heym JH, Schaeffer E, Rollema H, Lu Y, Mansbach RS, Chambers LK, Rovetti CC, Schulz DW, Tingley FD III, O'Neill BT (2005) Varenicline: an alpha4beta2 nicotinic receptor partial agonist for smoking cessation. J Med Chem 48:3474-3477

Cole BJ, Robbins TW (1987) Amphetamine impairs the discriminative performance of rats with dorsal noradrenergic bundle lesions on a 5-choice serial reaction time task: new evidence for central dopaminergic-noradrenergic interactions. Psychopharmacol Berl 91:458-466

Davis TJ, de Fiebre CM (2006) Alcohol's actions on neuronal nicotinic acetylcholine receptors. Alcohol Res Health 29:179185

Day M, Pan JB, Buckley MJ, Cronin E, Hollingsworth PR, Hirst WD, Navarra R, Sullivan JP, Decker MW, Fox GB (2007) Differential effects of ciproxifan and nicotine on impulsivity and attention measures in the 5-choice serial reaction time test. Biochem Pharmacol 73:1123-1134

De Vries TJ, Schoffelmeer AN, Binnekade R, Vanderschuren LJ (1999) Dopaminergic mechanisms mediating the incentive to seek cocaine and heroin following long-term withdrawal of IV drug self-administration. Psychopharmacol Berl 143:254-260

Di Chiara G, Imperato A (1988) Drugs abused by humans preferentially increase synaptic dopamine concentrations in the mesolimbic system of freely moving rats. Proc Natl Acad Sci U S A 85:5274-5278

Diergaarde L, Pattij T, Poortvliet I, Hogenboom F, de Vries W, AN Schoffelmeer, De Vries TJ (2008) Impulsive choice and impulsive action predict vulnerability to distinct stages of nicotine seeking in rats. Biol Psychiatry 63:301-308

Ericson M, Blomqvist O, Engel JA, Soderpalm B (1998) Voluntary ethanol intake in the rat and the associated accumbal dopamine overflow are blocked by ventral tegmental mecamylamine. Eur J Pharmacol 358:189-196

Ericson M, Engel JA, Soderpalm B (2000) Peripheral involvement in nicotine-induced enhancement of ethanol intake. Alcohol 21:37-47

Ericson M, Lof E, Stomberg R, Soderpalm B (2009) The smoking cessation medication varenicline attenuates alcohol and nicotine interactions in the rat mesolimbic dopamine system. J Pharmacol Exp Ther 329:225-230

Ford MM, Fretwell AM, Nickel JD, Mark GP, Strong MN, Yoneyama N, Finn DA (2009) The influence of mecamylamine on ethanol and sucrose self-administration. Neuropharmacology $57: 250-258$

Frishman WH (2009) Smoking cessation pharmacotherapy. Ther Adv Cardiovasc Dis 3:287-308

Gonzales D, Rennard SI, Nides M, Oncken C, Azoulay S, Billing CB, Watsky EJ, Gong J, Williams KE, Reeves KR (2006) Varenicline, an alpha4beta2 nicotinic acetylcholine receptor partial agonist, vs sustained-release bupropion and placebo for smoking cessation: a randomized controlled trial. JAMA 296:47-55

Gulick D, Gould TJ (2008) Varenicline ameliorates ethanol-induced deficits in learning in C57BL/6 mice. Neurobiol Learn Mem 90:230-236

Hendrickson LM, Zhao-Shea R, Tapper AR (2009) Modulation of ethanol drinking-in-the-dark by mecamylamine and nicotinic acetylcholine receptor agonists in C57BL/6J mice. Psychopharmacol Berl 204:563-572

Jerlhag E, Grotli M, Luthman K, Svensson L, Engel JA (2006) Role of the subunit composition of central nicotinic acetylcholine receptors for the stimulatory and dopamine-enhancing effects of ethanol. Alcohol Alcohol 41:486-493
Jorenby DE, Hays JT, Rigotti NA, Azoulay S, Watsky EJ, Williams KE, Billing CB, Gong J, Reeves KR (2006) Efficacy of varenicline, an alpha4beta2 nicotinic acetylcholine receptor partial agonist, vs placebo or sustained-release bupropion for smoking cessation: a randomized controlled trial. JAMA 296:56-63

Krishnan-Sarin S, Reynolds B, Duhig AM, Smith A, Liss T, McFetridge A, Cavallo DA, Carroll KM, Potenza MN (2007) Behavioral impulsivity predicts treatment outcome in a smoking cessation program for adolescent smokers. Drug Alcohol Depend 88:79-82

Larsson A, Jerlhag E, Svensson L, Soderpalm B, Engel JA (2004) Is an alpha-conotoxin MII-sensitive mechanism involved in the neurochemical, stimulatory, and rewarding effects of ethanol? Alcohol 34:239-250

Le A, Shaham Y (2002) Neurobiology of relapse to alcohol in rats. Pharmacol Ther 94:137-156

Levin ED, McClernon FJ, Rezvani AH (2006) Nicotinic effects on cognitive function: behavioral characterization, pharmacological specification, and anatomic localization. Psychopharmacol Berl 184:523-539

Lof E, Olausson P, deBejczy A, Stomberg R, McIntosh JM, Taylor JR, Soderpalm B (2007) Nicotinic acetylcholine receptors in the ventral tegmental area mediate the dopamine activating and reinforcing properties of ethanol cues. Psychopharmacol Berl 195:333-343

Marshall DL, Redfern PH, Wonnacott S (1997) Presynaptic nicotinic modulation of dopamine release in the three ascending pathways studied by in vivo microdialysis: comparison of naive and chronic nicotine-treated rats. J Neurochem 68:1511-1519

McKee SA, Harrison EL, O'Malley SS, Krishnan-Sarin S, Shi J, Tetrault JM, Picciotto MR, Petrakis IL, Estevez N, Balchunas E (2009) Varenicline reduces alcohol self-administration in heavydrinking smokers. Biol Psychiatry 66:185-190

Mihalak KB, Carroll FI, Luetje CW (2006) Varenicline is a partial agonist at alpha4beta2 and a full agonist at alpha7 neuronal nicotinic receptors. Mol Pharmacol 70:801-805

Mirza NR, Stolerman IP (1998) Nicotine enhances sustained attention in the rat under specific task conditions. Psychopharmacol Berl 138:266-274

Nadal R, Chappell AM, Samson HH (1998) Effects of nicotine and mecamylamine microinjections into the nucleus accumbens on ethanol and sucrose self-administration. Alcohol Clin Exp Res 22:1190-1198

Neugebauer NM, Zhang Z, Crooks PA, Dwoskin LP, Bardo MT (2006) Effect of a novel nicotinic receptor antagonist, $N, N^{\prime}$ dodecane-1,12-diyl-bis-3-picolinium dibromide, on nicotine selfadministration and hyperactivity in rats. Psychopharmacol Berl 184:426-434

Niaura R, Jones C, Kirkpatrick P (2006) Varenicline. Nat Rev Drug Discov 5:537-538

Nisell M, Nomikos GG, Svensson TH (1994) Systemic nicotineinduced dopamine release in the rat nucleus accumbens is regulated by nicotinic receptors in the ventral tegmental area. Synapse 16:36-44

O'Connor EC, Parker D, Rollema H, Mead AN (2010) The alpha4beta2 nicotinic acetylcholine-receptor partial agonist varenicline inhibits both nicotine self-administration following repeated dosing and reinstatement of nicotine seeking in rats. Psychopharmacol Berl 208:365-376

Patterson F, Jepson C, Strasser AA, Loughead J, Perkins KA, Gur RC, Frey JM, Siegel S, Lerman C (2009) Varenicline improves mood and cognition during smoking abstinence. Biol Psychiatry 65:144-149

Pattij T, Janssen MC, Vanderschuren LJ, Schoffelmeer AN, van Gaalen MM (2007) Involvement of dopamine D1 and D2 receptors in the nucleus accumbens core and shell in inhibitory response control. Psychopharmacol Berl 191:587-598 
Rezvani AH, Levin ED (2001) Cognitive effects of nicotine. Biol Psychiatry 49:258-267

Robbins TW (2002) The 5-choice serial reaction time task: behavioural pharmacology and functional neurochemistry. Psychopharmacol Berl 163:362-380

Rollema H, Chambers LK, Coe JW, Glowa J, Hurst RS, Lebel LA, Lu Y, Mansbach RS, Mather RJ, Rovetti CC, Sands SB, Schaeffer E, Schulz DW, Tingley FD III, Williams KE (2007) Pharmacological profile of the alpha4beta2 nicotinic acetylcholine receptor partial agonist varenicline, an effective smoking cessation aid. Neuropharmacology 52:985-994

Rollema H, Hajos M, Seymour PA, Kozak R, Majchrzak MJ, Guanowsky V, Horner WE, Chapin DS, Hoffmann WE, Johnson DE, McLean S, Freeman J, Williams KE (2009) Preclinical pharmacology of the alpha4beta2 nAChR partial agonist varenicline related to effects on reward, mood and cognition. Biochem Pharmacol 78:813-824

Scheurich A (2005) Neuropsychological functioning and alcohol dependence. Curr Opin Psychiatry 18:319-323

Shaham Y, Shalev U, Lu L, De WH, Stewart J (2003) The reinstatement model of drug relapse: history, methodology and major findings. Psychopharmacol Berl 168:3-20
Soderpalm B, Ericson M, Olausson P, Blomqvist O, Engel JA (2000) Nicotinic mechanisms involved in the dopamine activating and reinforcing properties of ethanol. Behav Brain Res 113:85-96

Sofuoglu M (2010) Cognitive enhancement as a pharmacotherapy target for stimulant addiction. Addiction 105:38-48

Steensland P, Simms JA, Holgate J, Richards JK, Bartlett SE (2007) Varenicline, an alpha4beta2 nicotinic acetylcholine receptor partial agonist, selectively decreases ethanol consumption and seeking. Proc Natl Acad Sci U S A 104:12518-12523

Tonstad S (2006) Smoking cessation efficacy and safety of varenicline, an alpha4beta2 nicotinic receptor partial agonist. J Cardiovasc Nurs 21:433-436

Tonstad S, Tonnesen P, Hajek P, Williams KE, Billing CB, Reeves KR (2006) Effect of maintenance therapy with varenicline on smoking cessation: a randomized controlled trial. JAMA 296:64-71

van Gaalen MM, Brueggeman RJ, Bronius PF, Schoffelmeer AN, Vanderschuren LJ (2006) Behavioral disinhibition requires dopamine receptor activation. Psychopharmacol Berl 187:73-85

Wonnacott S (1997) Presynaptic nicotinic ACh receptors. Trends Neurosci 20:92-98 